\title{
Self-referential reflective activity and its relationship with rest: a PET study
}

\author{
Arnaud D’Argembeau, ${ }^{\text {a, }}$ Fabienne Collette, ${ }^{\mathrm{a}}$ Martial Van der Linden, ${ }^{\mathrm{a}, \mathrm{b}}$ Steven Laureys, ${ }^{\mathrm{c}}$ Guy Del Fiore, ${ }^{\mathrm{c}}$ \\ Christian Degueldre, ${ }^{c}$ Andre' Luxen, ${ }^{c}$ and Eric Salmon ${ }^{c}$ \\ ${ }^{a}$ Department of Cognitive Sciences, University of Liège, Boulevard du Rectorat, 3 (B33), 4000 Liège, Belgium \\ ${ }^{\mathrm{b}}$ Cognitive Psychopathology and Neuropsychology Unit, University of Geneva, Switzerland \\ ${ }^{c}$ Cyclotron Research Centre, University of Liège, Belgium
}

\begin{abstract}
This study used positron emission tomography (PET) to identify the brain substrate of self-referential reflective activity and to investigate its relationship with brain areas that are active during the resting state. Thirteen healthy volunteers performed reflective tasks pertaining to three different matters (the self, another person, and social issues) while they were scanned. Rest scans were also acquired, in which subjects were asked to simply relax and not think in a systematic way. The mental activity experienced during each scan was assessed with rating scales. The results showed that, although self-referential thoughts were most frequent during the selfreferential task, some self-referential reflective activity also occurred during rest. Compared to rest, performing the reflective tasks was associated with increased blood flow in the dorsomedial prefrontal cortex, the left anterior middle temporal gyrus, the temporal pole bilaterally, and the right cerebellum; there was a decrease of blood flow in right prefrontal regions and in medial and right lateral parietal regions. In addition, the ventromedial prefrontal cortex (VMPFC) (1) was more active during the self-referential reflective task than during the other two reflective tasks, (2) showed common activation during rest and the self-referential task, and (3) showed a correlation between cerebral metabolism and the amount of self-referential processing. It is suggested that the VMPFC is crucial for representing knowledge pertaining to the self and that this is an important function of the resting state. D 2004 Elsevier Inc. All rights reserved.
\end{abstract}

Keywords: Medial prefrontal cortex - Self-referential processing - Rest - Neuroimaging - PET

\section{INTRODUCTION}

Recent neuroimaging studies have begun to unravel the neural basis of various aspects of self-referential processing, such as recognizing one's own face (Keenan et al., 2000; Kircher et al., 2001), detecting one's own first name (Perrin et al., 2005), attributing actions to oneself (Farrer et al., 2003; Ruby and Decety, 2001), reflecting on one's own abilities, personality traits or attitudes (Fossati et al., 2003; Johnson et al., 2002; Kelley et al., 2002; Kjaer et al., 2002; Schmitz et al., 2004), and remembering previous judgements about oneself (Lou et al., 2004). Many of these studies point to cortical midline structures as brain regions essential for representing, monitoring, evaluating, and integrating self-referential stimuli (Northoff and Bermpohl, 2004). In particular, the medial prefrontal cortex (MPFC) seems to be important for reflecting on knowledge about the self. For instance, the MPFC has repeatedly been found to be activated when people reflect on their own personality traits as compared to when they reflect on the traits of another person or when they perform other kinds of semantic processing (Fossati et al., 2003; Johnson et al., 2002; Kelley et al., 2002; Kjaer et al., 2002; Schmitz et al., 2004).

Several studies and meta-analyses have revealed that levels of blood flow in medial prefrontal and parietal cortices decrease when people perform various cognitive tasks compared to a resting baseline (Binder et al., 1999; Mazoyer et al., 2001; McKiernan et al., 2003; Shulman et al., 1997; Wicker et al., 2003). The consistency with which these task-induced deactivations are observed across a wide variety of studies suggests that these decreases in cerebral blood flow are caused by interruption of processes that usually occur in the resting state (Gusnard and Raichle, 2001). According to this view, "rest" is not at all restful but is a state of organized, functional brain activity that is suspended or interrupted during various goal-directed behaviors. The mental activity that occurs during "rest" could involve many processes, including monitoring of external environment and body state (Gusnard and Raichle, 2001); attention to self-referential information (Wicker et al., 2003); stimulus-independent thought (McGuire et al., 1996); planning and problem-solving (Binder et al., 1999). These processes are in no way mutually exclusive, and it seems quite likely that different brain areas that are active during the resting state are involved to different degrees in these and other processes. With regard to the MPFC, Wicker et al. (2003) proposed that this structure is involved when subjects are engaged in tasks that refer to internally triggered processes versus tasks that refer to external percepts (internally versus externally directed attention), and that both self-referential reflective tasks and the resting state involve some amount of internally directed attention in order to retrieve and inspect information about the self. Gusnard and Raichle (2001) further 
suggested that the ventral and dorsal parts of the MPFC may serve different functions, with the ventromedial prefrontal cortex (VMPFC) being involved in the integration of cognitive and emotional processes while the dorsomedial prefron-tal cortex (DMPFC) is involved in self-referential mental activity. However, a substantial number of recent neuroimaging studies have reported activation of the VMPFC during self-referential reflective tasks (Johnson et al., 2002; Kelley et al., 2002; Schmitz et al., 2004). Northoff and Bermpohl (2004) recently proposed that the VMPFC is involved in the continuous representation of self-referential stimuli, whereas the DMPFC is involved in the evaluation of these stimuli. However, the precise relationship between these processes and the resting state is not yet well understood.

The purpose of the present study was precisely to further examine brain regions that are active during the resting state and to better investigate their relationship with brain regions that support self-referential reflective activity. More specifically, given that previous studies comparing the resting state with goal-directed cognitive processing used tasks in which subjects' attention was directed towards externally presented stimuli (Binder et al., 1999; Mazoyer et al., 2001; McKiernan et al., 2003; Shulman et al., 1997; Wicker et al., 2003), the first aim of this study was to examine whether the increases and decreases in brain activity that occur when performing these tasks are also found when rest is compared to tasks involving internally instead of externally directed attention (i.e., tasks that do not require processing of external stimuli). To this end, rest was compared to reflective tasks in which subjects' mental activity was exclusively internal (i.e., no stimuli were presented during the scans and no responses were required), so that these tasks were closely matched to the resting state in this respect. Our second purpose was to identify the brain regions that are specifically involved in self-referential reflective activity and to determine whether these regions are also active during the resting state. Accordingly, three reflective conditions were used in which participants had to focus their mental activity on specific topics pertaining either to the self or to other matters (i.e., another person or social issues). The brain substrate of selfreferential reflective activity was identified, firstly, by comparing the self-referential reflective task to reflective tasks pertaining to other matters and, secondly, by correlating cerebral metabolism with the percentages of selfreferential thought (as assessed by rating scales) across all conditions. Finally, the cerebral areas that are commonly activated by rest and by the self-referential reflective task were determined by means of a conjunction analysis.

\section{METHODS}

\section{Subjects}

Thirteen right-handed volunteers from the University of Liège (7 women, 6 men; age range, 21 to 28 years) participated in the study. None had any significant history of neurological or psychiatric problems nor did they use any medication. The study was approved by the Ethics Committee of the Faculty of Medicine of the University of Liège. After the study was described in detail for the subjects, they gave their informed consent in writing. Data from one male participant were discarded because he did not follow the experimental instructions properly.

\section{Reflective tasks}

Three reflective conditions were used: reflection on one's own personality traits ("self" condition); reflection on the personality traits of another person ("other" condition); reflection on social issues ("society" condition). Subjects were scanned three times for each condition, the topics being slightly different for each scan: for the "self" condition, subjects were asked to think of their own personality traits in three different contexts (profession, family, and social relations); for the "other" condition, they were asked to think of the personality traits of three different persons (the French president Jacques Chirac, the French singer Johnny Hallyday, and the Belgian princess Mathilde); for the "society" condition, they were asked to think about three different social issues (social security, the right to vote, and globalization of trade). A fourth condition was also included, which corresponded to rest. In this condition, subjects were asked to simply relax and not think in a systematic way but to open themselves to any images, thoughts or memories that appeared spontaneously. Three rest scans were administered randomly.

For each scan, the procedure was as follows: $45 \mathrm{~s}$ before the beginning of the scan, the experimenter asked subjects to close their eyes and relax; $15 \mathrm{~s}$ later (i.e., $30 \mathrm{~s}$ before the scan), the experimenter read the instructions pertaining to the reflective task or the rest period (e.g., "Now you will be asked to think about yourself for about $2 \mathrm{~min}$. More specifically, I would like you to consider the traits and attitudes you have in the context of social relations. Try to think about your traits and attitudes, about your personality, in your relationship with others."). The length of the instructions was similar for the four conditions (mean number of words was 49 for the "self" condition, 49 for the "other" condition, 48 for the "society" condition, and 46 for the "rest" condition). Following the experimenter's instructions, subjects began reflecting on the topic $5 \mathrm{~s}$ before the scan and ended their 
reflection $5 \mathrm{~s}$ after the scan, thereby thinking about each topic for $100 \mathrm{~s}$. Subjects kept their eyes closed for the entire scan; no stimuli were presented and no motor responses were required. Thus, unlike earlier studies that compared rest to goal-directed cognitive tasks, subjects' activity during the reflective tasks was exclusively internal (i.e., the tasks did not require the processing of external stimuli) so that the reflective conditions and rest were closely matched in this respect. Immediately after each scan, subjects were asked to verbally report the thoughts, images, and/or memories they had had while they were reflecting on the topic. Then they rated several aspects of the mental activity they had experienced during the scan, including amount of visual images; thoughts (i.e., total amount of thoughts experienced, whatever their content); relative amount of thoughts about the self; thoughts about other persons; memories; physical sensations. Ratings were made on 10-point scales (e.g., I experienced visual images: 1, not at all; 10, all the time). Subjects also evaluated the amount of time they had thoughts, images, and/ or memories that were directly related to the topic they were asked to think about (in percentage of total scan time). Verbal reports and ratings were made without time constraints.

The day before the positron emission tomography (PET) session, each subject was asked to reflect on three topics, one for each experimental condition ("self", "other", "society"), and to report the thoughts and rate the mental activity they had experienced while reflecting on these topics. These trials were done in order to check that subjects clearly understood the distinction between the three reflective tasks (none of these trials were used for the PET session) and to familiarize them with the rating scales.

\section{Positron emission tomography scanning}

PET data were acquired on a Siemens CTI 951 R 16/31 scanner (Siemens, Erlangen) in 3-D mode. The subject's head was stabilized by a thermoplastic facemask secured to the head holder (Truscan imaging, Annapolis, MD), and a venous catheter was inserted in a left antebrachial vein. First, a 20-min transmission scan was acquired for attenuation correction using three rotating sources of $68 \mathrm{Ge}$. Then, regional cerebral blood flow $(\mathrm{rCBF})$, taken as a marker of local neuronal activity (Jueptner and Weiller, 1995), was assessed during twelve emission scans. Each scan consisted of two frames: a 30-s background frame and a 90-s acquisition frame. The slow intravenous water $\left(\mathrm{H}_{2}{ }^{15} \mathrm{O}\right)$ infusion began $10 \mathrm{~s}$ before the second frame. Six mCi (222 MBq) were injected for each scan, in $5 \mathrm{cc}$ saline, over a period of $20 \mathrm{~s}$. The infusion was totally automated in order not to disturb the subject during the scanning period. Data were reconstructed using a Hanning filter (cutoff frequency: 0.5 cycles/pixel) and corrected for attenuation and background activity. The four experimental conditions were pseudo-randomly distributed between subjects, with the constraints that all conditions were presented once before their presentation was repeated and no condition was administered twice in succession.

\section{Data analysis}

PET data were analyzed using statistical parametric mapping (SPM2; Welcome Department of Imaging Neuroscience, London, UK; http://www.fil.ion.ucl.ac.uk/spm) implemented in MATLAB (Mathworks Inc., Sherborn, MA). For each subject, all scans were realigned together, then normalized to a standard PET template using the same transformations (Frackowiak et al., 1997). Finally, PET images were smoothed using a Gaussian kernel of $16 \mathrm{~mm}$ full width at half maximum to accommodate inter-subject differences in gyral and functional anatomy and to suppress high frequency noise in the images. Such transformations of the data allow for voxelby-voxel averaging of data across subjects and for direct cross-reference to the anatomical features in a standard stereotactic space (Talairach and Tournoux, 1988).

The covariance analysis subject-specific design matrix used in this study included three scans per subject for each condition. However, the verbal reports obtained immediately after each scan revealed that seven participants failed to think about one or more topic(s). Accordingly, the scans relating to these topics were not included in the analyses (in total: 2 scans for the "self" condition, 6 scans for the "other" condition, and 7 scans for the "society" condition). The design matrix considered block effect and individual global flow as confounds. The resulting set of voxel values for each contrast constituted a map of the $t$ statistic [SPM(t)], transformed to the unit normal distribution $[\operatorname{SPM}(Z)]$. The "rest" condition was compared to the other three conditions in order to determine the cerebral areas that are activated (rest $-($ self + other + society)) and deactivated ((self + other + society) - rest) during the resting state as compared to goal-directed reflective activity. ${ }^{1}$ In addition, the "self" condition was compared to "other" and "society" conditions to determine the neural basis of self-referential reflective activity (self - (other + society)). The reverse contrast ((other + society) - self) was performed to identify cerebral areas involved in reflective activity relating to matters other than the self. Finally, in order to determine cerebral areas common to the "self" and "rest" conditions, a conjunction analysis was performed in which the changes in cerebral activity common to the comparison of the "self" versus "other" conditions and the

\footnotetext{
${ }^{1}$ When the "rest" condition was compared to each of the other three conditions separately, the cerebral areas that were activated and deactivated were similar in each case, so that we only report analyses with the "self," "other," and "society" conditions grouped together.
} 
"rest" versus "society" conditions were assessed ((self - other) AND (rest - society)). ${ }^{2}$ When performing this conjunction analysis, an inclusive masking procedure was applied to ensure that activation was observed in each individual contrast (at $P<0.05$ ).

A SPM thresholded at $P<0.001$ (voxel level) was used, with further correction for multiple comparisons $(P<$ $0.05)$. Based on previous neuroimaging studies, we predicted that self-referential reflective activity would be associated with activation in the VMPFC (Johnson et al., 2002; Kelley et al., 2002; Kjaer et al., 2002; Schmitz et al., 2004). Accordingly, small volume correction (SVC; 10 -mm-radius sphere, centered at $\mathrm{x}=4, \mathrm{y}=52, \mathrm{z}=6$ ) was applied when looking for activation in this predicted region.

\section{RESULTS}

\section{Verbal reports and rating scales}

A qualitative analysis of the content of verbal reports revealed that subjects generally conformed to the instructions pertaining to the reflective tasks. An example of verbal report for each condition is presented in Table 1.

Table 1 : Examples of verbal reports

\begin{tabular}{|l|l|}
\hline Self & $\begin{array}{l}\text { In my relations, I try to be always present for my friends, to listen to them and to be helpful for them. I also like to laugh with } \\
\text { them, to liven things up. I also thought that I am frank, if a friend does or says something that seems wrong to I tell her or him } \\
\text { immediately, and conversely, I like people to be frank with me and not to criticize me behind my back. }\end{array}$ \\
\hline Other & $\begin{array}{l}\text { I thought that Johnny Hallyday is someone who does a lot for his fans, in particular during his concerts. He is likeable and he } \\
\text { hasn't let it go to his head despite his fame. I also thought that sometimes he is not very intelligent, sometimes he says stupid } \\
\text { things, but overall he is nice and close to his fans. }\end{array}$ \\
\hline Society & $\begin{array}{l}\text { I thought that the right to vote is the foundation of democracy and is essential for a society to function properly. Some people } \\
\text { consider that voting is a constraint and think that it is a waste of time. But I think that it's really important! And our ancestors had } \\
\text { to fight to establish the right to vote. I also thought that people sometimes vote without knowing the program of the party they } \\
\text { chose, people should be more careful when voting. }\end{array}$ \\
\hline Rest & $\begin{array}{l}\text { I thought about nothing in particular. . At the beginning I had some images of my house. . Then I thought about what I did } \\
\text { yesterday. . I also thought that I have to go shopping this afternoon. }\end{array}$ \\
\hline
\end{tabular}

Mean ratings for the characteristics of the mental activity experienced in the four conditions are presented in Table 2. These ratings were analyzed with repeated measures ANOVAs (see Table 2 for F and P values). Planned comparisons between the four conditions were further conducted, with significance levels corrected for multiple comparisons using the Bonferroni adjustment $(P<0.0083)$. For visual images, the only significant difference was between the "other" and "society" conditions. For thoughts, the reflective conditions (self, other, society) received higher ratings than the "rest" condition. Although self-related thoughts and memories were most frequent in the "self" condition, the rating scales indicated that some self-referential reflective activity also occurred in the other three conditions. This was especially the case in the "rest" condition, in which thoughts about the self were significantly more frequent than in the "other" condition. Thoughts about other persons were more frequent in the "other" condition than in the "society" and "rest" conditions, and they were more frequent in the "self condition than in the "rest' condition. Physical sensations were more frequent in the "rest' condition than in the three other conditions. Finally, the amount of time participants spent thinking about the topics did not differ between the "self," "other," and "society" conditions (means were 77\%, 72\%, and 72\%, respectively), $\mathrm{F}(2$, 22) $=2.62, P=0.10$

\footnotetext{
${ }^{2}$ A conjunction analysis between the contrasts self - society and rest - other revealed similar findings. In addition, a conjunction analysis made by combining the "other" and "society" conditions, that is, (self - (other + society)) AND (rest - (other + society)), also revealed similar findings. Accordingly, we only report the conjunction between the contrasts self - other and rest - society.
} 
Table 2: Mean ratings (and standard deviations) for the characteristics of the mental activity experienced during the "self," "other," "society," and "rest" conditions

\begin{tabular}{|c|c|c|c|c|c|c|}
\hline & Self & Other & Society & Rest & $\mathrm{F}(3,33)$ & $\mathrm{P}$ \\
\hline Visual images & $5.97(0.38)^{\mathrm{a}}$ & $6.30(0.51)^{\mathrm{b}}$ & $4.42(0.42)^{b}$ & $4.25(0.57)^{\mathrm{c}}$ & 6.13 & 0.002 \\
\hline Thoughts & $5.89(0.76)^{\mathrm{a}}$ & $5.96(0.81)^{b}$ & $6.40(0.64)^{\mathrm{c}}$ & $3.86(0.54)^{\mathrm{a}, \mathrm{b}, \mathrm{c}}$ & 8.01 & 0.0004 \\
\hline Memories & $7.07(0.36)^{\mathrm{a}, \mathrm{b}, \mathrm{c}}$ & $2.13(0.43)^{\mathrm{a}}$ & $3.76(0.58)^{b}$ & $2.39(0.40)^{\mathrm{c}}$ & 40.38 & 0.0001 \\
\hline Thoughts about self & $8.57(0.30)^{\mathrm{a}, \mathrm{b}}$ & $1.85(0.34)^{\mathrm{a}}$ & $3.29(0.31)^{b}$ & $4.22(0.58)^{\mathrm{a}}$ & 49.50 & 0.0001 \\
\hline Thoughts about other & $6.54(0.45)^{\mathrm{a}}$ & $7.58(0.60)^{\mathrm{b}}$ & $4.79(0.69)^{\mathrm{b}}$ & $4.02(0.67)^{\mathrm{a}, \mathrm{b}}$ & 8.83 & 0.0002 \\
\hline Physical sensations & $2.38(0.30)^{\mathrm{a}}$ & $2.17(0.42)^{b}$ & $2.38(0.51)^{\mathrm{c}}$ & $3.50(0.55)^{\mathrm{a}, \mathrm{b}, \mathrm{c}}$ & 5.10 & 0.005 \\
\hline
\end{tabular}

Superscript letters indicate significant differences between conditions: means within a row that share superscripts were significantly different from each other (at $P<0.0083$ ); means with different superscripts did not differ.

\section{PET data}

$($ Self + other + society $)$ - rest

Table 3 summarizes the principal areas that showed increases and decreases in rCBF for the three reflective conditions in comparison to the "rest' condition (see also Fig. 1). Increases of rCBF were observed in the DMPFC (BA 8/9), the left anterior middle temporal gyrus (BA 21), the temporal pole bilaterally (BA 38), and the right cerebellum. Plots of activity in the DMPFC for each condition showed that relative activation occurred in all reflective conditions compared to rest (see Fig. 2).

Rest-(self + other + society)

The comparison of the "rest' condition to the three reflective tasks revealed a large network of brain areas that encompassed various frontal and parietal regions, mainly in the right hemisphere

(Table 3, Fig. 1). Specifically, decreased rCBF when performing the reflective tasks was seen in the right lateral orbitofrontal gyrus (BA 11), the middle frontal gyrus (bilaterally: BA 10; right: BA 9), the right superior frontal sulcus, the right inferior parietal lobe and supramarginal gyrus (BA 40), the right cuneus (BA 7), and the left precuneus (BA 7).

Self - (other + society)

Consistent with our predictions, the VMPFC (BA 10/32) was more active in the "self" condition than in the other two reflective conditions (Table 4, Fig. 3).

$($ Other + society $)-$ self

The comparison of the "other" and "society" conditions with the "self" condition did not reveal any significant change in $\mathrm{rCBF}$ (at $P<0.05$, corrected for multiple comparisons).

Other - society

The contrast between the "other" and "society" conditions did not reveal any significant change in $\mathrm{rCBF}$ (at $P<$ 0.05 , corrected for multiple comparisons).

\section{Conjunction analysis}

The cerebral areas that are common to rest and the self-referential reflective task were determined by performing a conjunction analysis between the contrasts self - other and rest - society. This analysis revealed common activations in the VMPFC (BA 10/32; Table 4, Fig. 3). Plots of activity in the VMPFC for each condition showed that relative activation occurred in the "self" and "rest" conditions, whereas local blood flow was decreased in the "other" and "society" conditions (see Fig. 4).

\section{Correlation analyses}

Although the rating scales indicated that self-referential reflective activity was most frequent in the "self" condition, they also showed that there were substantial self-related thoughts in the other three conditions. Furthermore, the "self" condition was characterized not only by a large amount of self-related reflective activity but also by some thoughts about other persons. Considering these findings, we sought to isolate the cerebral regions that are specifically related to reflective activity about the self by correlating the percentages of selfreferential thoughts (as assessed by the rating scales) and cerebral metabolism, across all conditions. The results 
showed that the amount of self-referential reflective activity correlated with the cerebral metabolism in the VMPFC (BA 10/32; see Table 4; Fig. 3). By contrast, there was no brain region in which cerebral metabolism was significantly correlated with the amount of thoughts concerning other persons.

Table 3: Increases and decreases in brain activity during the three reflective tasks compared to rest

\begin{tabular}{|c|c|c|c|c|}
\hline \multirow[t]{2}{*}{ Brain areas } & \multicolumn{3}{|c|}{$\begin{array}{l}\text { Stereotactic } \\
\text { coordinates }\end{array}$} & \multirow[t]{2}{*}{ Z score } \\
\hline & $\mathrm{x}$ & $\mathrm{y}$ & z & \\
\hline \multicolumn{5}{|l|}{$($ Self + other + society $)-$ rest } \\
\hline Dorsomedial prefrontal cortex (BA 8/9) & -8 & 47 & 44 & 6.18 \\
\hline $\mathrm{L}$ anterior middle temporal gyrus (BA 21) & -55 & 5 & -25 & 5.92 \\
\hline \multirow[t]{2}{*}{$\mathrm{L}$ and $\mathrm{R}$ temporal poles (BA 38) } & -38 & 20 & -30 & 5.31 \\
\hline & 38 & 28 & -30 & 4.97 \\
\hline $\mathrm{R}$ cerebellum & 20 & -61 & -19 & 5.70 \\
\hline \multicolumn{5}{|l|}{ Rest $-($ self + other + society $)$} \\
\hline R lateral orbitofrontal gyrus (BA 11) & 26 & 56 & -16 & 6.23 \\
\hline R middle frontal gyrus (BA 9) & 46 & 27 & 32 & 5.67 \\
\hline \multirow[t]{2}{*}{$\mathrm{R}$ and $\mathrm{L}$ middle frontal gyrus (BA 10) } & 42 & 46 & -7 & 5.47 \\
\hline & -40 & 56 & -8 & 4.63 \\
\hline $\mathrm{R}$ superior frontal sulcus & 24 & 46 & 23 & 5.17 \\
\hline $\mathrm{R}$ inferior parietal lobe (BA 40) & 57 & -41 & 41 & 5.95 \\
\hline R supramarginal gyrus (BA 40) & 59 & -43 & 28 & 5.22 \\
\hline R cuneus (BA 7) & 16 & -74 & 31 & 5.22 \\
\hline L Precuneus (BA 7) & -8 & -62 & 47 & 5.11 \\
\hline
\end{tabular}

Coordinates refer to the local maxima as indicated by the highest $\mathrm{Z}$ score within an area of activation ( $P<0.05$, corrected for multiple comparisons). $\mathrm{L}=$ left hemisphere; $\mathrm{R}=$ right hemisphere. $\mathrm{x}, \mathrm{y}, \mathrm{z}$ (in $\mathrm{mm}$ ) refer to coordinates in the Talairach space (Talairach and Tournoux, 1988).

Fig. 1. Increases $(A)$ and decreases $(B)$ in brain activity during the three reflective tasks (self + other + society) compared to rest.

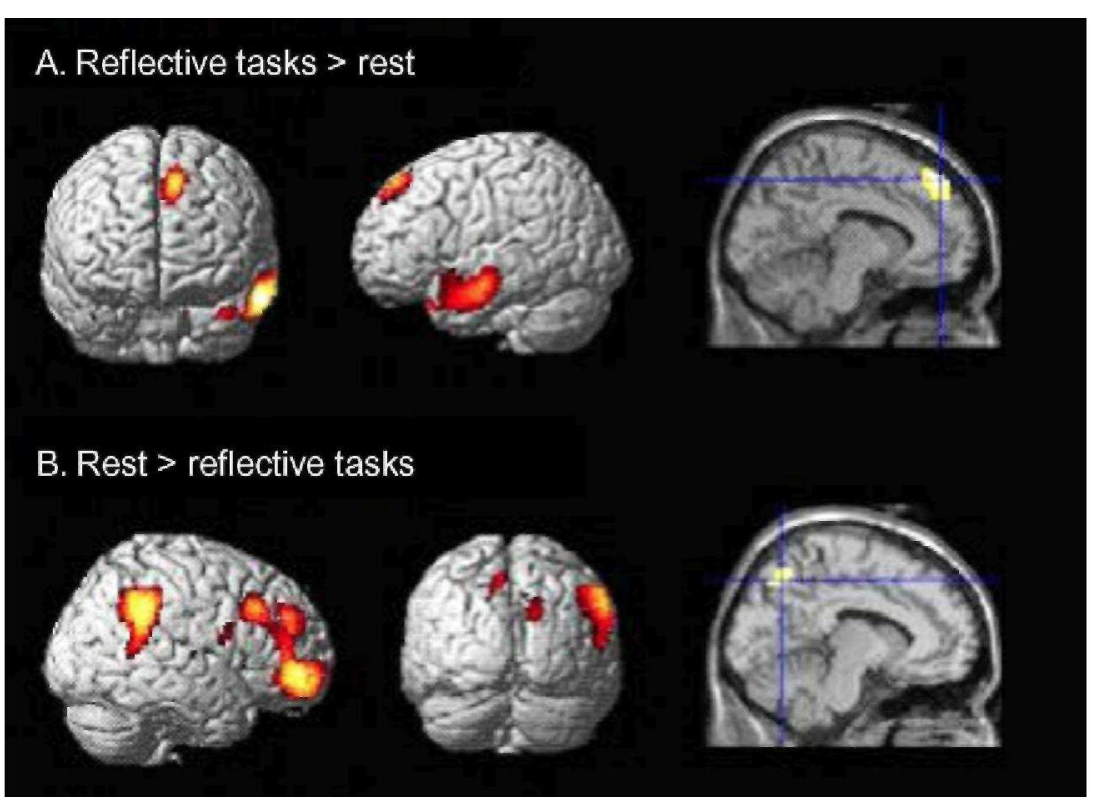


Fig. 2. Plots of activity in the DMPFC (at $x=-8, y=47, z=44$ ) for each condition.

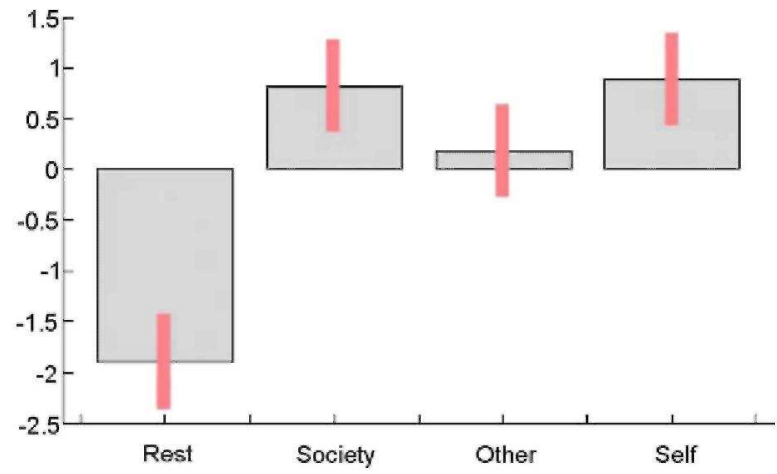

Table 4: Brain regions (1) that showed activation during the "self" condition compared to the "other" and "society" conditions, (2) that showed activation common to the "self" and "rest" conditions, and (3) in which cerebral metabolism correlated with amount of self-referential thoughts

\begin{tabular}{ll}
\hline Brain areas & $\begin{array}{l}\text { Stereotactic } \\
\text { coordinates }\end{array}$ \\
\cline { 2 - 3 } & Z score \\
& y $\mathrm{z}$
\end{tabular}

(1) self - (other + society)

Ventromedial prefrontal cortex (BA 10/32) $\quad \begin{array}{lllll}-4 & 52 & -1 & 3.73\end{array}$

(2) (Self - other) AND (rest - society)

Ventromedial prefrontal cortex (BA 10/32) $\quad \begin{array}{llll}0 & 45 & -2 & 4.09\end{array}$

(3) Correlation with amount of self-referential thoughts

Ventromedial prefrontal cortex (BA 10/32) $\quad \begin{array}{lllll}-4 & 52 & -1 & 4.19\end{array}$

Coordinates refer to the local maxima as indicated by the highest $\mathrm{Z}$ score within an area of activation (SVC at voxel $P$ value $<0.05$ ). $\mathrm{x}, \mathrm{y}, \mathrm{z}$ (in $\mathrm{mm}$ ) refer to coordinates in the Talairach space (Talairach and Tournoux, 1988).

Fig. 3. Brain regions (A) that showed activation during the "self" condition compared to the "other" and "society" conditions, (B) that showed activation common to the "self" and "rest" conditions, and (C) in which cerebral metabolism correlated with amount of self-referential thoughts. 


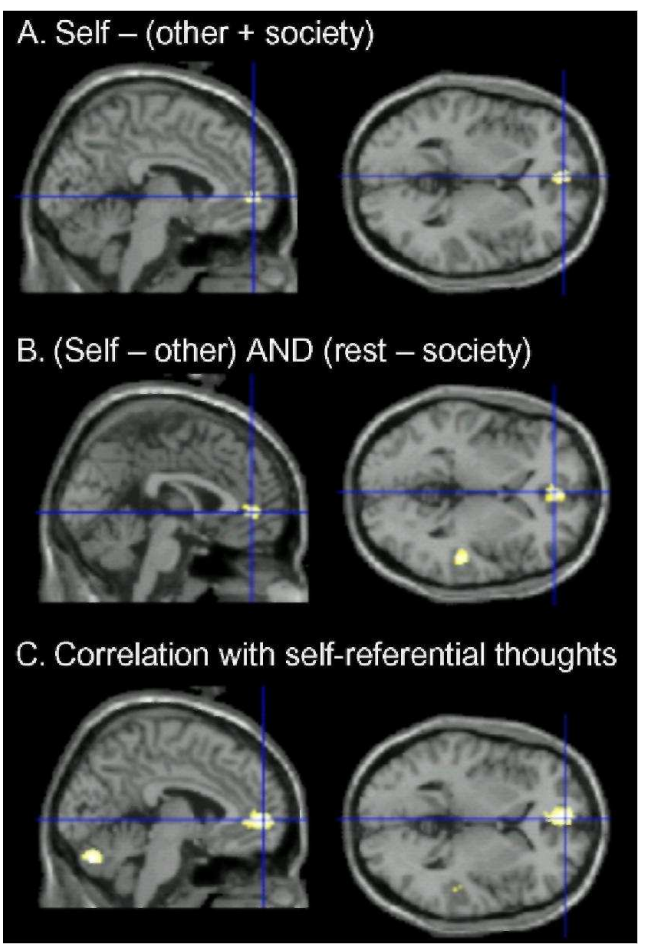

\section{DISCUSSION}

The objective of this study was to identify the brain substrate of self-referential reflective activity and to investigate its relationship with brain areas that are active during the resting state. Compared to rest, goaldirected reflective activity was associated with increased blood flow in the DMPFC, the left middle temporal gyrus, the temporal pole bilaterally, and the right cerebellum, and with decreased blood flow in right prefrontal regions and in medial and right lateral parietal regions. In addition, the VMPFC was more active during the self-referential reflective task than during reflective tasks pertaining to other matters, showed common activation during rest and the selfreferential task, and showed a correlation between cerebral metabolism and amount of self-referential processing. In this section, we first will discuss the increases and decreases in brain activity that were observed during the reflective tasks as compared to rest. We then will examine our results concerning self-referential reflective activity and its relationship with the resting state.

\section{Increases in brain activity during the reflective tasks}

The network of brain regions that showed increased activity during the three reflective tasks compared to rest includes two regions (the DMPFC and the temporal pole) that are involved in mentalizing or "theory of mind" capacity (Frith and Frith, 2003; Gallagher and Frith, 2003). These two brain regions may serve different functions. The MPFC, and particularly, though not exclusively, the DMPFC (BA 8/9), is activated by tasks that involve attributing goals and intentions to other people (Fletcher et al., 1995; Gallagher et al., 2000; Happe et al., 1996). In addition, activation of the DMPFC occurs when subjects attend to their own emotional reactions to picture stimuli (Gusnard et al., 2001). In light of these findings, Frith and Frith (2003) suggested that this region is activated whenever people are attending to certain states of the self or others. This is consistent with our findings, given that the three reflective tasks we used required attributing some traits to the self or another person or issue. It should be noted that, contrary to the present findings, the DMPFC typically shows decreases in brain activity during goal-directed cognitive tasks, as compared to rest (Gusnard and Raichle, 2001; McKiernan et al., 2003). Nonetheless, Gusnard et al. (2001) found increased activity in the DMPFC when participants attended to their emotions, compared to a control task of visual fixation, and they suggested that this region was involved in self-referential mental activity. In the present study, however, the increase in activity in the DMPFC compared to rest was not specific to the self-referential task, and the cerebral metabolism in that region did not correlate with the amount of self-referential processing. Also, a recent study (Iacoboni et al., 2004) found an increase in activity in the DMPFC compared to rest in a task that did not specifically involve self-referential processing (looking at video clips depicting everyday social scenes). Thus, the function of the DMPFC may be to monitor states or characteristics of various matters including, but not limited to, the self.

A second region that has been found to be associated with mentalizing is the temporal pole. This region (especially on the left) is frequently activated in studies of semantic processing (Vandenberghe et al., 1996, 2002), and it is also active during the recollection of personal semantic and episodic memories such as the recognition of familiar faces and voices (Nakamura et al., 2000, 2001) and retrieval from autobiographical 
memory (Fink et al., 1996; Maguire and Mummery, 1999; Piefke et al., 2003; Piolino et al., 2004). Frith and Frith (2003) suggested that the temporal pole is concerned with generating, on the basis of past experience, a wider semantic and emotional context for the material currently being processed, whose function would be to aid in the interpretation of this material. In our study, increased activity during the reflective tasks was also observed in the right cerebellum. This region has been found to be activated during autobiographical memory retrieval (Andreasen et al., 1999; Piefke et al., 2003; Piolino et al., 2004), and it has been suggested that it is part of a corticocerebellar memory network whose role is to initiate and maintain the coordination or ongoing updating of retrieval processes (Andreasen et al., 1999). Thus, overall, the activation of the temporal poles and of the right cerebellum that was observed in the present study may reflect the retrieval of knowledge and memories (both personal and more general) that are used to form a conscious representation of the specific characteristics of the self or other matters, and activation of the DMPFC may refer to processes involved in reflecting about these characteristics.

Fig. 4. Plots of activity in the VMPFC (at $x=0, y=45, z=-2)$ for each condition.

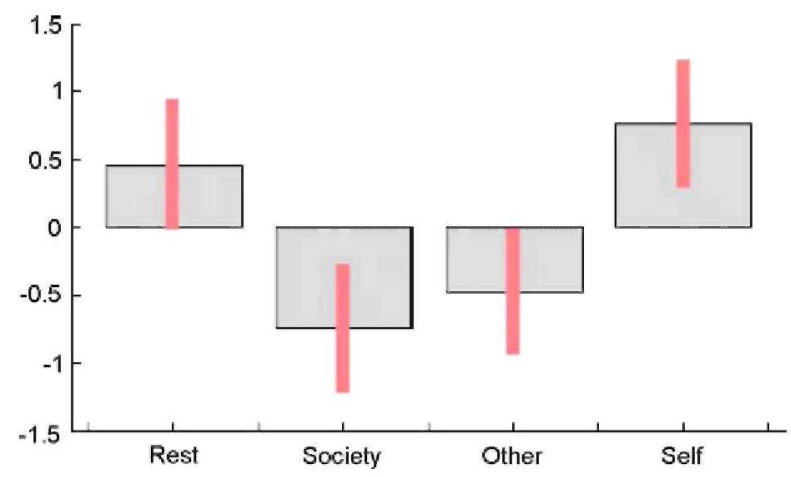

\section{Decreases in brain activity during the reflective tasks}

Previous studies have revealed that medial parietal regions (posterior cingulate cortex and adjacent precuneus), as well as medial and lateral prefrontal regions, show decreases in activity during various cognitive tasks compared to rest (Binder et al., 1999; Mazoyer et al., 2001; McKiernan et al., 2003; Shulman et al., 1997). Also, left hemisphere regions showed more extensive deactivation than right hemisphere regions. In the present study, medial parietal areas (precuneus) showed decreased activity during the reflective tasks, which is consistent with these previous studies. By contrast, other regions that showed decreased brain activity were predominantly located in the right hemisphere. A crucial difference between our study and previous ones concerns the direction of attention during the cognitive tasks to which the resting state was compared. In the present study, subjects' activity during the reflective tasks was exclusively internal (i.e., subjects had their eyes closed and no stimuli were presented nor was any response required during the scans). Thus, the reflective conditions were closely matched to the resting state in this respect, the main difference between the two being related to the goal-directed versus unconstrained nature of mental activity. By contrast, in earlier studies, the cognitive tasks to which the resting state was compared not only involved goal-directed mental activity but also required processing of externally presented stimuli. It might therefore be that the predominantly left hemisphere deactivation that had been observed in these studies is related to the orientation of attention and processing resources towards external stimuli.

Be that as it may, medial parietal areas showed decreased activity during the goal-directed tasks compared to rest in both this study and earlier ones. It has been argued that these areas continuously gather information about the world around, and possibly within, us (Gusnard and Raichle, 2001) and represent the self in relationship with the outside world (Damasio, 1999). Decreases in blood flow also occurred in the right parietal lobe. Lesions in the right parietal lobe induce alterations of body awareness such as neglect and anosognosia or asomatognosia (Berlucchi and Aglioti, 1997). In addition, neuroimaging studies showed activation of parietal structures (more extensive in the right hemisphere) when participants make decisions concerning the body-centered location of visual and somatic sensory stimuli (Galati et al., 2001; Vallar et al., 1999). Also, it has been found that focal electrical stimulation of the right inferior parietal cortex in a patient who was undergoing evaluation for epilepsy treatment induces illusory own-body perceptions (Blanke et al., 2002). Thus, the right inferior parietal lobe appears to be essential for the representation of bodily states and of the body as the center of an egocentric experiential space (Vogeley and Fink, 2003), and these representations may be crucial to having a "minimal self" (Gallagher, 2000), "core self" (Damasio, 1999), or "observing self" (Baars et al., 2003) defined as "consciousness of oneself as an immediate subject of experience, unextended in time" (Gallagher, 2000, p. 15).

A large area of the right prefrontal cortex was also more active during rest than in the reflective tasks in the 
present study. It has been proposed that the right prefrontal cortex plays an important role in "autonoetic consciousness," which is the capacity that allows us to represent mentally and become aware of our continued existence across subjective time; past, present, and future (Wheeler et al., 1997). Neuropsychological evidence indicates that damage to the right prefrontal cortex often results in deficits in the recollection of the past, the introspection of the present, and the anticipation of the future (Stuss and Levine, 2002; Wheeler et al., 1997). The verbal reports we collected indicate that part of the mental activity experienced during rest dealt with the retrieval of past experiences (e.g., what subjects did in the morning or the day before) and future prospects (e.g., what they planned to do the next day), and these may be related to right prefrontal activation.

Thus, whereas the medial and right lateral parietal regions that were active during rest may reflect the continuous representation and monitoring of bodily states and of the external world in relation to the self, the right prefrontal cortex may be related to awareness of the self as an entity existing over time, and both these processes may be attenuated when attention is intentionally directed to specific conceptual representations (whether they pertain to the self or other matters). It should be noted that these frontoparietal regions are not only deactivated by goaldirected cognitive tasks but also show markedly lower metabolism in different unconscious states such as deep sleep, coma, persistent vegetative state, and general anesthesia, thus, suggesting that they play a crucial role in conscious experience of both the inner and outer world (Baars et al., 2003).

\section{Self-referential reflective activity and its relationship with rest}

The VMPFC was more active when participants were asked to reflect on their own personality traits than when they reflected on the personality traits of other persons or on social issues. This is consistent with previous studies that showed activation of the VMPFC during self-referential processing as compared to other kinds of semantic processing (Johnson et al., 2002; Kelley et al., 2002; Schmitz et al., 2004) and with the hypothesis that self-referential material is represented in this region (Northoff and Bermpohl, 2004). The use of rating scales to assess the mental activity experienced by subjects while they were scanned also enabled us to show that the cerebral metabolism in the VMPFC correlated with the amount of self-referential thoughts but not with the amount of thoughts pertaining to other persons, thus, suggesting that this region is specifically related to some aspects of self-referential processing. Referring to the fundamental distinction between two facets of the self, the self as subject of a person's experience versus the self as knowledge or beliefs about oneself (Gallagher, 2000; Leary and Tangney, 2003), we suggest that the VMPFC is crucially involved in the second aspect, that is, in representing what one knows about oneself (e.g., one's own personality traits and attitudes). This mental representation of oneself may rely on both general knowledge about one's own personality and specific memories of past experiences, but it is probably mainly semantic in nature. Indeed, behavioral and neuropsychological evidence suggests that episodic memory is not necessary for representing and evaluating one's own personality traits (Klein et al., 2002).

The resting state probably involves many processes of different kinds (e.g., monitoring the external environment and body states, planning future actions) that rely on different brain regions. Among others, one important function of rest may be to represent self-referential information. From a phenomenological point of view, our study indicates that the resting state is indeed characterized by a substantial amount of self-referential thought. It has been suggested that self-referential processing during the resting state relies on the DMPFC (Gusnard and Raichle, 2001). However, the present study, together with other recent studies

(Johnson et al., 2002; Kelley et al., 2002; Schmitz et al., 2004), indicates that the VMPFC also plays a role in self-referential processing. Whereas the DMPFC may help represent current states of both the self and others (Frith and Frith, 2003; Gusnard and Raichle, 2001), such as one's own current emotional reactions (Gusnard et al., 2001), the function of the VMPFC may be to represent more stable (semantic) knowledge pertaining to the self (i.e., stable personality traits and dispositions as opposed to transient states). Our PET data revealing common activation in the VMPFC during rest and a self-referential reflective task further suggest that this function may be an important aspect of the resting state. The resting state may enable people to represent knowledge pertaining to themselves, thus helping them to maintain a stable self-concept over time.

Acknowledgments: This study was supported by the Belgian National Fund for Scientific Research (FNRS) and the Government of the French-Speaking Community of Belgium (Actions de Recherche Con-certe'es, Grant 99/04-246). A.D. is a Postdoctoral Researcher at the FNRS. F.C. and S.L. are Research Associates at the FNRS.

\section{References}

Andreasen, N.C., O’Leary, D.S., Paradiso, S., Cizadlo, T., Arndt, S., Watkins, G.L., Boles Ponto, L.L., Hichwa, R.D., 1999. The cerebellum plays a role in conscious episodic memory retrieval. Hum. Brain Mapp. 8, 226-234.

Baars, B.J., Ramsoy, T.Z., Laureys, S., 2003. Brain, conscious experience and the observing self. Trends Neurosci. 26, 671-675.

Berlucchi, G., Aglioti, S., 1997. The body in the brain: neural bases of corporeal awareness. Trends Neurosci. 20, 560-564.

Binder, J.R., Frost, J.A., Hammeke, T.A., Bellgowan, P.S.F., Rao, S.M., Cox, R.W., 1999. Conceptual processing during 
Published in: Neuroimage (2005), vol. 25, iss. 2, pp. 616-624

Status: Postprint (Author's version)

the conscious resting state: a functional MRI study. J. Cogn. Neurosci. 11, 80-93.

Blanke, O., Ortigue, S., Landis, T., Seeck, M., 2002. Stimulating illusory own-body perceptions. Nature 419, $269-270$.

Damasio, A., 1999. The Feeling of What Happens: Body and Emotion in the Making of Consciousness. Harcourt Brace, New-York.

Farrer, C., Franck, N., Georgieff, N., Frith, C.D., Decety, J., Jeannerod, M., 2003. Modulating the experience of agency: a positron emission tomography study. NeuroImage 18, 324-333.

Fink, G.R., Markowitsch, H.J., Reinkemeier, M., Bruckbauer, T., Kessler, J., Heiss, W.D., 1996. Cerebral representation of one's own past: neural networks involved in autobiographical memory. J. Neurosci. 16, 4275-4282.

Fletcher, P.C., Happe, F., Frith, U., Baker, S.C., Dolan, R.J., Frackowiak, R.S.J., Frith, C.D., 1995. Other minds in the brain: a functional imaging study of btheory of mindQ in story comprehension. Cognition 57, 109-128.

Fossati, P., Hevenor, S.J., Graham, S.J., Grady, C., Keightley, M.L., Craik, F., Mayberg, H., 2003. In search of the emotional self: an fMRI study using positive and negative emotional words. Am. J. Psychiatry 160, 1938-1945.

Frackowiak, R., Friston, K., Frith, C., Dolan, R., Mazziotta, J.C., 1997.Human Brain Function. Academic Press, London.

Frith, U., Frith, C.D., 2003. Development and neurophysiology of mentaliz-ing. Philos. Trans. R. Soc. London, Ser. B Biol. Sci. 358, 459473. Galati, G., Committeri, G., Sanes, J.N., Pizzamiglio, L., 2001. Spatial coding of visual and somatic sensory information in body-centred coordinates. Eur. J. Neurosci. 14, 737-746.

Gallagher, S., 2000. Philosophical conceptions of the self: implications for cognitive sciences. Trends Cogn. Sci. 4, 14-21.

Gallagher, H.L., Frith, C.D., 2003. Functional imaging of dtheory of mindT. Trends Cogn. Sci. 7, 77-83.

Gallagher, H.L., Happe, F., Brunswick, N., Fletcher, P.C., Frith, U., Frith, C.D., 2000. Reading the mind in cartoons and stories: an fMRI study of dtheory of the mindT in verbal and nonverbal tasks. Neuropsychologia 38, 11-21.

Gusnard, D.A., Raichle, M.E., 2001. Searching for a baseline: functional imaging and the resting human brain. Nat. Rev., Neurosci. 2, 685694.

Gusnard, D.A., Akbudak, E., Shulman, G.L., Raichle, M.E., 2001. Medial prefrontal cortex and self-referential mental activity: relation to a default mode of brain function. Proc. Natl. Acad. Sci. U. S. A. 98, 4259-4264.

Happe, F., Ehlers, S., Fletcher, P., Frith, U., Johansson, M., Gillberg, C., Dolan, R., Frackowiak, R., Frith, C., 1996. dTheory of mindT in the brain. Evidence from a PET scan study of Asperger syndrome. NeuroReport 8, 197-201.

Iacoboni, M., Lieberman, M.D., Knowlton, B.J., Molnar Szakacs, I., Moritz, M., Throop, C.J., Fiske, A.P., 2004. Watching social interactions produces dorsomedial prefrontal and medial parietal BOLD fMRI signal increases compared to a resting baseline. NeuroImage $21,1167-1173$

Johnson, S.C., Baxter, L.C., Wilder, L.S., Pipe, J.G., Heiserman, J.E., Prigatano, G.P., 2002. Neural correlates of self-reflection. Brain 125, $1808-1814$.

Jueptner, M., Weiller, C., 1995. Review: does measurement of regional cerebral blood flow reflect synaptic activity? Implications for PET and fMRI. NeuroImage 2, 148-156.

Keenan, J.P., Wheeler, M.A., Gallup, G.G., Pascual-Leone, A., 2000. Self-recognition and the right prefrontal cortex. Trends Cogn. Sci. 4 , $338-344$.

Kelley, W.M., Macrae, C.N., Wyland, C.L., Caglar, S., Inati, S., Heatherton, T.F., 2002. Finding the self?: an event-related fMRI study. J. Cogn. Neurosci. 14, 785-794

Kircher, T.T.J., Senior, C., Phillips, M.L., Rabe Hesketh, S., Benson, P.J., Bullmore, E.T., Brammer, M., Simmons, A., Bartels, M., David, A.S., 2001. Recognizing one's own face. Cognition 78, B1-B15.

Kjaer, T.W., Nowak, M., Lou, H.C., 2002. Reflective self-awareness and conscious states: PET evidence for a common midline parietofrontal core. NeuroImage 17, 1080-1086.

Klein, S.B., Rozendal, K., Cosmides, L., 2002. A social-cognitive neuro-science analysis of the self. Soc. Cogn. 20, $105-135$.

Leary, M.R., Tangney, J.P., 2003. The self as an organizing construct in the behavioral and social sciences. In: Leary, M.R., Tangney, J.P. (Eds.), Handbook of Self and Identity. Guilford Press, New York, NY, pp. 3-14.

Lou, H.C., Luber, B., Crupain, M., Keenan, J.P., Nowak, M., Kjaer, T.W., Sackeim, H.A., Lisanby, S.H., 2004. Parietal cortex and representation of the mental self. Proc. Natl. Acad. Sci. U. S. A. 101, 6827-6832.

Maguire, E.A., Mummery, C.J., 1999. Differential modulation of a common memory retrieval network revealed by positron emission tomography. Hippocampus 9, 54-61.

Mazoyer, B., Zago, L., Mellet, E., Bricogne, S., Etard, O., Houde, O., Crivello, F., Joliot, M., Petit, L., Tzourio Mazoyer, N., 2001. Cortical networks for working memory and executive functions sustain the conscious resting state in man. Brain Res. Bull. 54, $287-298$.

McGuire, P.K., Paulesu, E., Frackowiak, R.S.J., Frith, C.D., 1996. Brain activity during stimulus independent thought. NeuroReport 7, 20952099

McKiernan, K.A., Kaufman, J.N., Kucera Thompson, J., Binder, J.R., 2003. A parametric manipulation of factors affecting task-induced deactivation in functional neuroimaging. J. Cogn. Neurosci. 15, 394-408.

Nakamura, K., Kawashima, R., Sato, N., Nakamura, A., Sugiura, M., Kato, T., Hatano, K., Ito, K., Fukuda, H., Schormann, T., Zilles, K., 2000 .

Functional delineation of the human occipito-temporal areas related to face and scene processing: a PET study. Brain 123, $1903-1912$. 
Nakamura, K., Kawashima, R., Sugiura, M., Kato, T., Nakamura, A., Hatano, K., Nagumo, S., Kubota, K., Fukuda, H., Ito, K., Kojima, S., 2001. Neural substrates for recognition of familiar voices: a PET study. Neuropsychologia 39, 1047-1054.

Northoff, G., Bermpohl, F., 2004. Cortical midline structures and the self. Trends Cogn. Sci. 8, 102-107.

Perrin, F., Maquet, P., Peigneux, Ph., Ruby, P., Degueldre, C., Balteau, E., Del Fiore, G., Moonen, G., Luxen, A., Laureys, S., 2005. Neural mechanisms involved in the detection of our first name: a combined ERPs and PET study. Neuropsychologia 43, $12-19$.

Piefke, M., Weiss, P.H., Zilles, K., Markowitsch, H.J., Fink, G.R., 2003. Differential remoteness and emotional tone modulate the neural correlates of autobiographical memory. Brain 126, 650-668.

Piolino, P., Giffard-Quillon, G., Desgranges, B., Che'telat, G., Baron, J.-C., Eustache, F., 2004. Re-experiencing old memories via hippocampus: a PET study of autobiographical memory. NeuroImage 22, 1371-1383.

Ruby, P., Decety, J., 2001. Effect of subjective perspective taking during simulation of action: a PET investigation of agency. Nat. Neurosci. 4, 546-550.

Schmitz, T.W., Kawahara-Baccus, T.N., Johnson, S.C., 2004. Metacogni-tive evaluation, self-relevance, and the right prefrontal cortex. Neuro-Image 22, 941-947.

Shulman, G.L., Fiez, J.A., Corbetta, M., Buckner, R.L., Miezin, F.M., Raichle, M.E., Petersen, S.E., 1997. Common blood flow changes across visual tasks: II. decreases in cerebral cortex. J. Cogn. Neurosci. 9, 648-663.

Stuss, D.T., Levine, B., 2002. Adult clinical neuropsychology: lessons from studies of the frontal lobes. Annu. Rev. Psychol. 53, $401-433$.

Talairach, J., Tournoux, P., 1988. Co-Planar Stereotaxic Atlas of the Human Brain: 3-Dimensional Proportional System. Thieme, Stuttgart.

Vallar, G., Lobel, E., Galati, G., Berthoz, A., Pizzamiglio, L., Le Bihan, D., 1999. A fronto-parietal system for computing the egocentric spatial frame of reference in humans. Exp. Brain Res. 124, 281-286.

Vandenberghe, R., Price, C., Wise, R., Josephs, O., Frackowiak, R.S.J., 1996. Functional anatomy of a common semantic system for words and pictures. Nature 383, 254-256.

Vandenberghe, R., Nobre, A.C., Price, C.J., 2002. The response of left temporal cortex to sentences. J. Cogn. Neurosci. 14, 550-560.

Vogeley, K., Fink, G.R., 2003. Neural correlates of the first-person-perspective. Trends Cogn. Sci. 7, 38-42.

Wheeler, M.A., Stuss, D.T., Tulving, E., 1997. Toward a theory of episodic memory: the frontal lobes and autonoetic consciousness. Psychol. Bull. 121, 331-354

Wicker, B., Ruby, P., Royet, J.P., Fonlupt, P., 2003. A relation between rest and the self in the brain? Brain Res. Brain Res. Rev. 43, 224230 . 